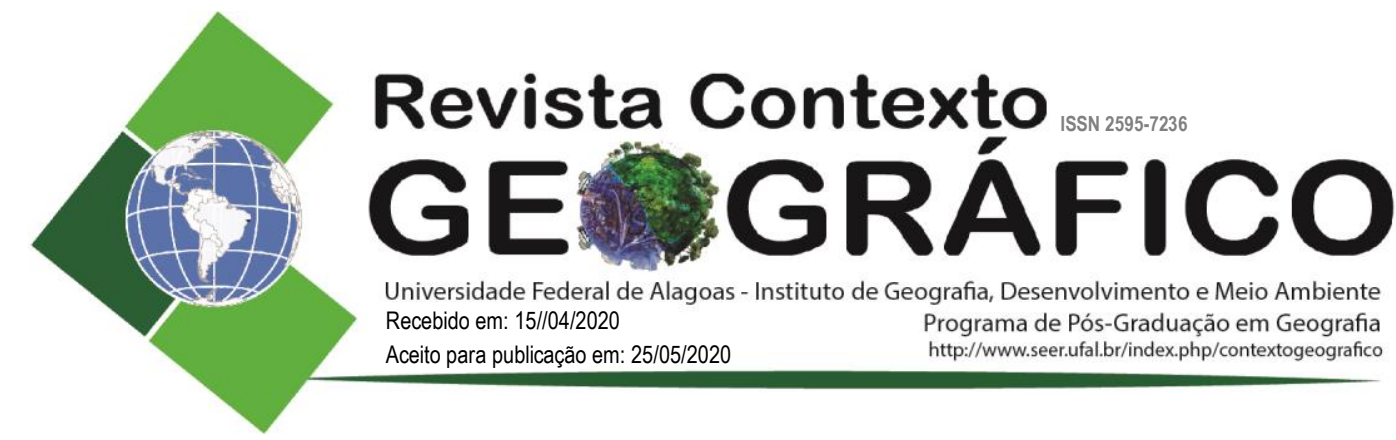

\title{
TURISMO VERSUS COMUNIDADES VULNERÁVEIS: METAMORFOSES URBANAS NA CAPITAL DO PARAÍSO DAS ÁGUAS
}

\author{
Jadson de Jesus Santos \\ Professor de Geografia da ECIT Izaura Falcão de Carvalho - SEECT, PB, Brasil \\ jadsongeo@gmail.com \\ Phellipe Cunha da Silva \\ Professor de Geografia da ECIT Izaura Falcão de Carvalho - SEECT, PB, Brasil \\ phellipecunha@hotmail.com
}

\begin{abstract}
RESUMO - Este artigo é fruto de pesquisa elaborada durante estudos de campo realizados na cidade de Maceió, Alagoas. São apresentados no decorrer do texto fatos e argumentos acerca das modificações na infraestrutura urbana da cidade, principalmente na execução da obra de reformulação do terminal portuário para recebimento de cruzeiros marítimos. Em decorrência disso, uma comunidade pesqueira, de existência pioneira na cidade, foi retirada e transferida do local com o argumento de melhor adequação da área, desconsiderando o fator de pertencimento do lugar pelas pessoas que ali residiam. Os resultados apresentados possuem relevância para fomentar estudos posteriores mostrando o quão é essencial o planejamento das cidades com apelo turístico voltado para a população local e suas necessidades, não descartando a importância do papel da atividade turística para uma cidade. Desse modo, acredita-se que as cidades com apelo turístico sejam também planejadas com funcionalidades para a população residente e não apenas para visitantes e turistas.
\end{abstract}

Palavras-chave: Infraestrutura urbana; Comunidade pesqueira; Pertencimento; Lugar.

\section{TOURISM VERSUS VULNERABLE COMMUNITIES: URBAN METAMORPHOSES IN THE CAPITAL OF THE WATER PARADISE}

\begin{abstract}
This article is the result of research developed during field studies conducted in the city of Maceio, Alagoas. During the text, facts and arguments about the modifications in the urban infrastructure of the city are presented, mainly in the execution of the work of reformulation of the port terminal to receive maritime cruises. As a result, a fishing community, a pioneer in the city, was removed and transferred from the locality with the argument of better adaptation of the area, disregarding the factor of belonging of the place by the people who lived there. The results presented are relevant to foster further studies showing how essential is the planning of cities with tourist appeal focused on the local population and their needs, not ruling out the importance of the role of tourism to a city. Thus, it is believed that cities with tourist appeal are also planned with functionalities for the resident population and not only for visitors and tourists.
\end{abstract}

Keywords: urban infrastructure; fishing community; belonging; place.

\section{CARACTERIZAÇÃO E EVOLUÇÃO DA MANCHA URBANA DA CIDADE DE MACEIÓ, ALAGOAS}

Conhecido como o Paraíso das Águas, o estado de Alagoas concentra dezenas de praias de águas mornas e cristalinas ao longo de uma costa de corais por cerca de 229 quilômetros de extensão. Sua capital, Maceió, é a porta de entrada de milhares de pessoas por ano que são atraídas por suas 
paisagens paradisíacas, segundo dados da Secretaria do Desenvolvimento Econômico e Turismo de Alagoas, foram 2,6 milhões em 2017 e 2,9 milhões de turistas em 2018. O município de Maceió abrange uma área de 510,655 km², com população estimada em 2019 de 1.018 .948 habitantes, segundo dados do IBGE. É o município de maior IDHM do estado de Alagoas com índice de 0,721, tido como alto, segundo o Programa das Nações Unidas para o Desenvolvimento - PNUD de 2010. A cidade de Maceió, apesar do alto IDHM, apresenta um dos maiores índices de pobreza do Brasil, entre as capitais. A distribuição de renda é desigual entre a população. Em relação à infraestrutura da cidade, os pontos mais críticos estão relacionados às condições de moradia das pessoas, principalmente, nas regiões de grota por toda a cidade.

A exclusão, má distribuição de renda, falta de emprego e elevação dos preços dos imóveis em diversas áreas da cidade, levou o crescimento de habitações subnormais nessas grotas entre a planície costeira e os tabuleiros, além dos vales escavados pelos rios, concentrando a maior parte da população de renda baixa da cidade. Segundo levantamento da Prefeitura de Maceió, havia, até a finalização do Plano Diretor - Lei Municipal no 5486 de 30/12/2005 -, em toda a cidade, 68 Zonas Especiais de Interesse Social, sendo que uma delas, o Complexo do Vale do Reginaldo, abrange 19 comunidades.

No quesito turismo, segundo levantamento de dados do Ministério do Turismo, em 2018 entre embarques e desembarques, a movimentação do aeroporto de Maceió chegou a 2.179.230 passageiros, número maior que em 2017, quando o número chegou a 2.067 .576 passageiros havendo um crescimento de $5,4 \%$ de um ano para o outro, sendo uma das principais rotas turísticas do nordeste brasileiro. Devido a isto, são feitos investimentos em áreas de relevância ao turismo na cidade, muitas vezes sendo desconsideradas as prioridades de investimentos do dinheiro público para as outras áreas da cidade causando um processo de gentrificação das áreas turísticas e, consequentemente, segregação social.

Há, na cidade de Maceió, um processo de gentrificação em diversos bairros, seja por motivos relacionados ao turismo (Vila de Pescadores do Jaraguá) e imobiliários (Ponta Verde e Pajuçara) como também por empreendimentos econômicos como a recente construção do Parque Shopping no bairro Cruz da Almas, que vem passando por um forte processo de investimentos infraestruturais com a construção de avenidas, viaduto e outros equipamentos urbanos que provocam a valorização e, por conseguinte - frente à gentrificação -, a expulsão de moradores com poderes aquisitivos limitados, devido ao encarecimento do custo de vida na região. Como no Jaraguá, segundo Marchioni (2016, p. 36), “o Bairro da Cruz das Almas passou a sofrer o resultado de disputas tornadas desiguais entre os agentes e as instituições, que em condições homólogas às respectivas distinções sociais, objetivam a conquista e o domínio do espaço urbano e imobiliário restante".

Para a análise na pesquisa, foi feito um recorte amostral da cidade de Maceió. Os Bairros Pajuçara, Ponta da Terra e Jaraguá (Figura 1) foram analisados devido a dinâmica de infraestrutura existente entre eles. Os três, próximos a pontos turísticos, possuem características bem distintas, apesar de estarem próximos. No tocante à população, juntos, possuem 15.325 habitantes (IBGE, 2010) - Jaraguá, 3.211 hab.; Ponta da Terra, 8.403 hab.; Pajuçara, 3.711 hab.

O bairro do Jaraguá é, para Maceió, o marco da formação e constituição da cidade. A construção do porto marítimo foi o principal fator para o surgimento e desenvolvimento da cidade. As ruas eram tomadas por trapiches ${ }^{1}$ e armazéns que favoreciam a circulação e movimentação das pessoas sendo, dessa maneira, um bairro comercial. Juntamente a isto, haviam bares e restaurantes que transformou o bairro em um centro boêmio até meados do século XX. Com a mudança da dinâmica da cidade de Maceió, o Jaraguá tornou-se obsoleto, ficando abandonado por muitos anos. 
Figura 1. Maceió: Área de Abrangência da Pesquisa

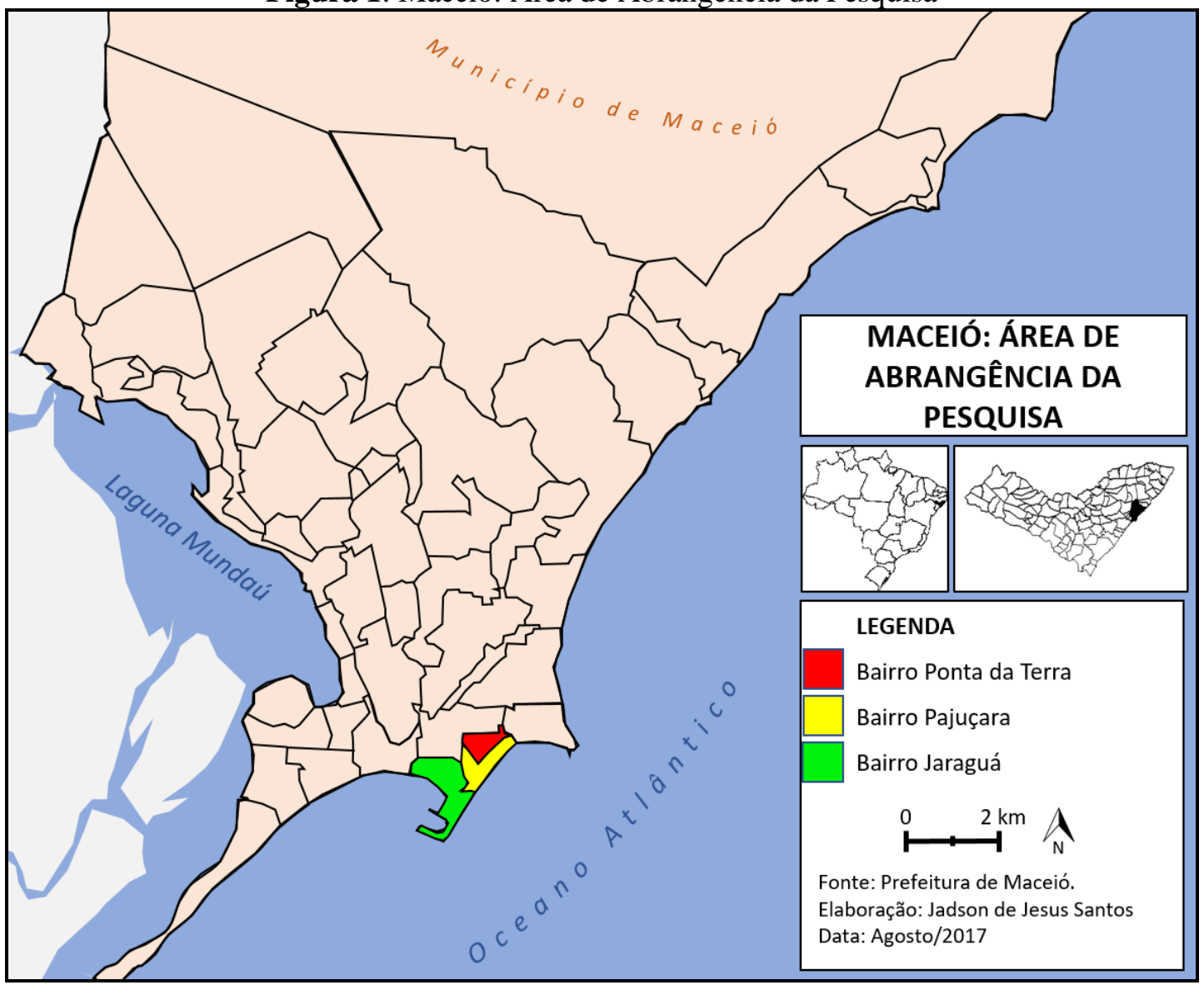

Fonte: Prefeitura de Maceió, 2017.

Desde o início desta década, o poder público está revitalizando o Jaraguá a fim de transformá-lo num grande centro cultural e ponto de acesso à turistas via cruzeiros marítimos que ancoram no porto. Em versos, a transcrição da criação do bairro é dita da seguinte forma:

Os cheiros do açúcar e suor se misturam. O barulho dos homens nus, da cintura para cima, carregando nas cabeças a "riqueza" de Maceió. Os trapiches solitários. Jaraguá, de dia, pulsa o vil metal que faz dos homens de negócios os importantes e imponentes sustentos desta nesga de terra que fora batizada pelos nossos ancestrais.

Um cheiro de perfume que exala da protuberância dos corpos femininos quase nus. A música e o cheiro ardente da bebida dos deuses gregos e, também, dos nordestinos. Jaraguá, de noite, pulsa orgia, alegria jovem, como no vinho servido por HEBE.

Os sobrados que resistem à ação do tempo teimam em conservar nossa história. Os monumentos que falam por si o que o tempo não vai conseguir apagar. A vida singular de Jaraguá, nos arrabaldes desta enseada, resume o começo de nossa origem: de dia o comércio - a vocação; de noite a diversão e arte - a devoção.

Assim, tudo começou! (CEFET-AL, 2002)

Desde a sua existência, o Jaraguá é carregado de história, é a base do surgimento da cidade de Maceió. De batismo, os Caetés denominaram o local "como a enseada do senhor (Jara - Senhor, 
Guará - Enseada). Tendo a primeira residência de arquitetura europeia construída em 1609 por Manuel Antônio Duro, então dono da sesmaria" (PEDROZA, 1998). Antônio Duro passou por maus bocados ao investir na região até então formada por alagadiços onde podia-se retirar água doce apenas dos poços cavados. Ao não conseguir prosperar a sesmaria, impostas em contrato pela coroa portuguesa, suas posses foram transferidas a Apolinário Padilha, responsável pela construção do engenho Massayó, principal responsável pelo enriquecimento e desenvolvimento do povoamento até torná-lo cidade.

O Jaraguá, desde o seu surgimento passa por altos e baixos relacionados ao seu uso. Atualmente, a região está sendo revitalizada com o intuito de reocupação de seus espaços. Mas, para isto está havendo também a desocupação de parte de seus espaços, principalmente de populações de baixa renda.

O bairro vizinho, Pajuçara, é, atualmente, o bairro de concentração de atrativos turístico, por, principalmente, concentrar a maior parte da rede hoteleira da cidade. Seu nome, homenagem à índia Pajuçara, significa: muito grande. A referência faz-se devido às grandes piscinas naturais que surgem nos arrecifes em horários de baixa da maré. Diferentemente do Jaraguá, Pajuçara é ocupada por moradores de classe média a alta e possui características de bairro consolidado.

Por fim, o bairro Ponta da Terra, também originário da fundação e crescimento do povoamento que deu origem à Maceió, é o que concentra a população mais pobre desta região. Inicialmente, o bairro surgiu com o povoamento de parte da Pajuçara pelos nobres donos de engenho os quais foram expulsando parte da população de pescadores para a região onde hoje é denominada de Ponta da Terra. Atualmente, o bairro é composto com 26 logradouros de casas mais simples e alguns pontos comerciais populares.

Além dos fatores econômicos, os citados acima influenciam, também, sobre onde e como darse-á o processo de surgimento de favelas. Segundo dados do IBGE, entre 1980 e 2000, Maceió foi a cidade brasileira como maior taxa de favelização do Brasil, com crescimento anual de 20,99\% da população vivendo em áreas de habitações subnormais. Segundo o Censo de 2010, realizado pelo IBGE, a cidade de Aracaju aparecia como a capital com menor índice de favelização, com 61.847 pessoas vivendo em habitações subnormais o que corresponde a $10,83 \%$ da população residente. Enquanto Maceió apresentava um total de 114.635 pessoas vivendo em favelas, o que corresponde a $12,29 \%$ da população total.

Maceió, por margear um oceano, possuía restrições, de uma das direções, à expansão, ao longo do tempo, sua expansão foi dada em direção ao interior. Os espaços consolidados de Maceió estão no entorno do centro, banhado pelo oceano Atlântico. Além dos já descritos, a concentração industrial a leste, em Maceió foi fator fundamental à expansão da cidade nessa região, como podemos visualizar na Figura 2.

É possível relatar que, devido à cidade de Maceió está constituída numa dinâmica de relevo costeiro rodeada por tabuleiros, a concentração da população mais pobre ficou nos vales, denominados de grotas, surgindo assim boa parte das atuais favelas da cidade. (Figuras 3 e 4).

A criação da rodovia BR 316, inicialmente com o intuito de ligação açucareira ao Porto de Maceió, seu projeto - datado de 1978 - de tornar-se uma Via Expressa nunca saiu do papel. O que seria uma via dupla com canteiro central que se estenderia por cerca de $18 \mathrm{~km}$, com a má gestão dos recursos à sua construção, transformou-se numa rodovia de pista simples que teve importante papel ao escoamento da produção açucareira. 
Figura 2. Maceió: Evolução da Mancha Urbana.

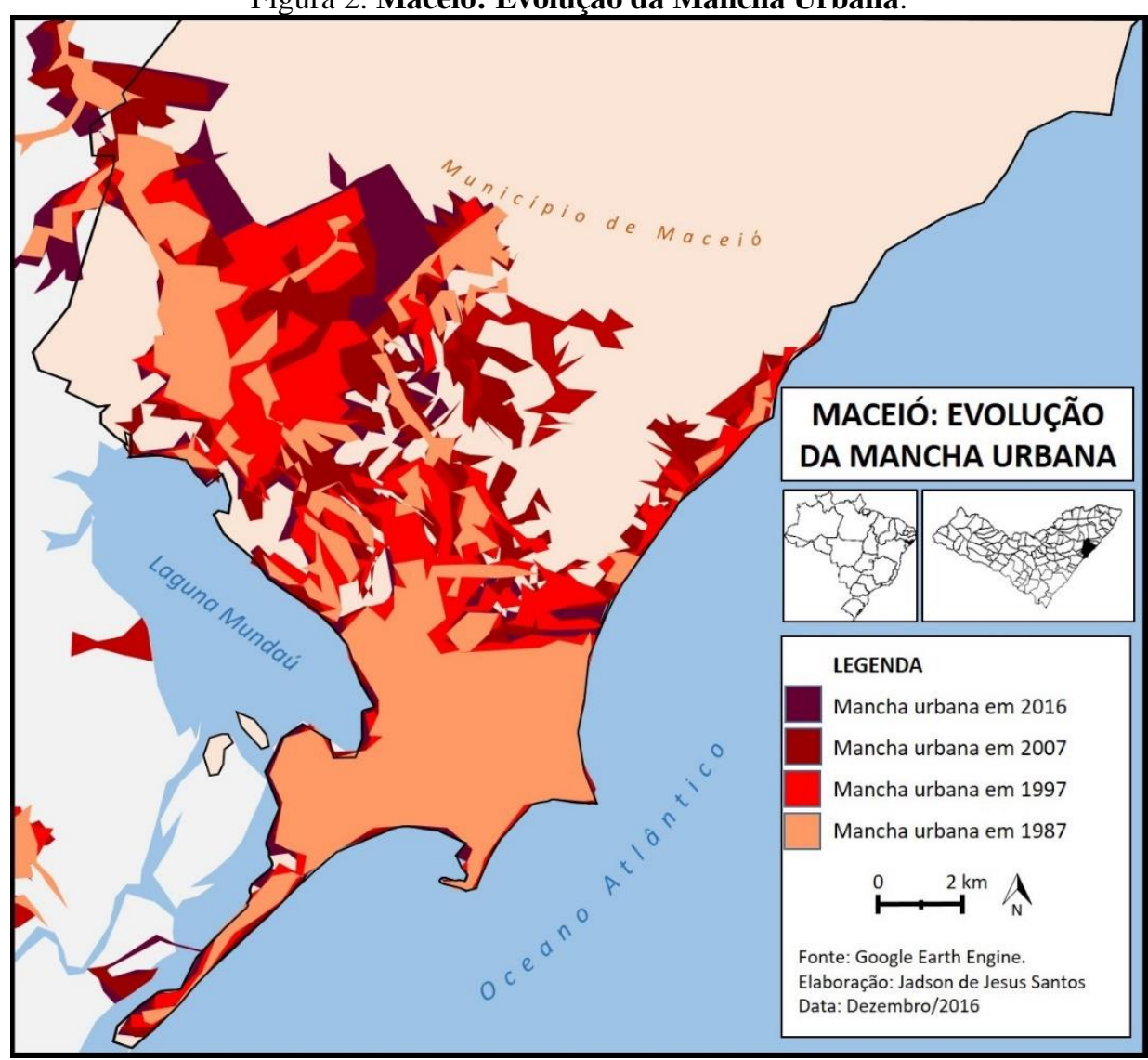

Fonte: Google Earth Engine, 2016.

Figura 3. Vale do Reginaldo, Maceió-AL.

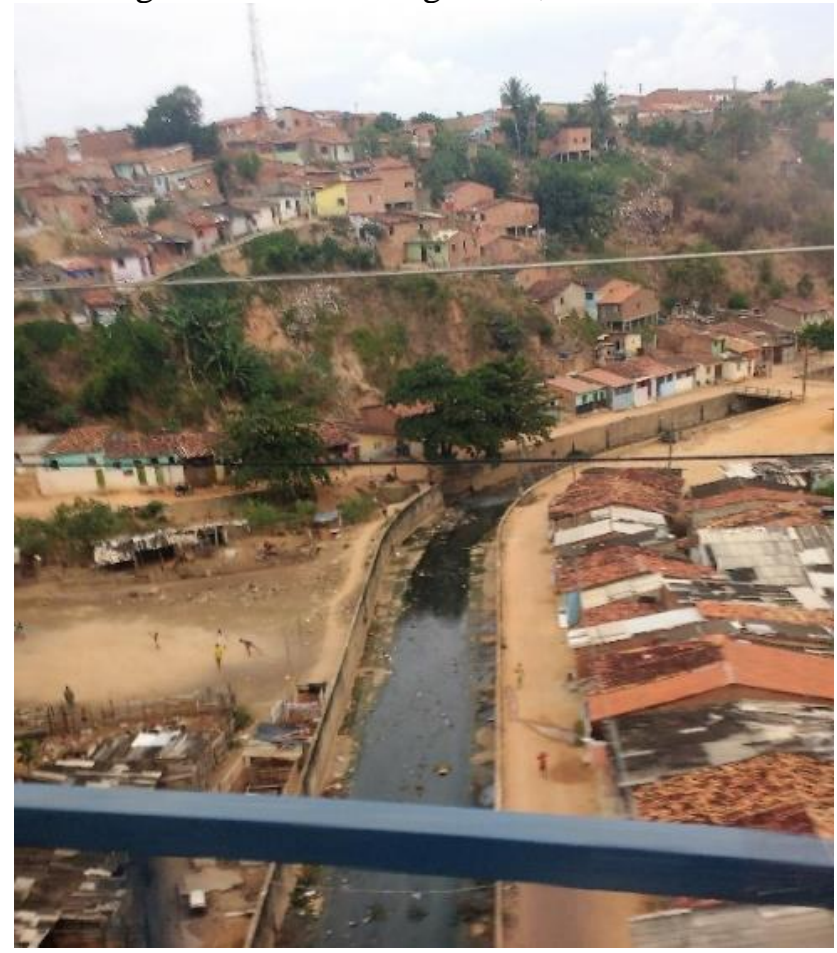

Acervo: Santos, J. J. (19/12/2016). 
Figura 4. Tabuleiro da Cambona, Maceió-AL.

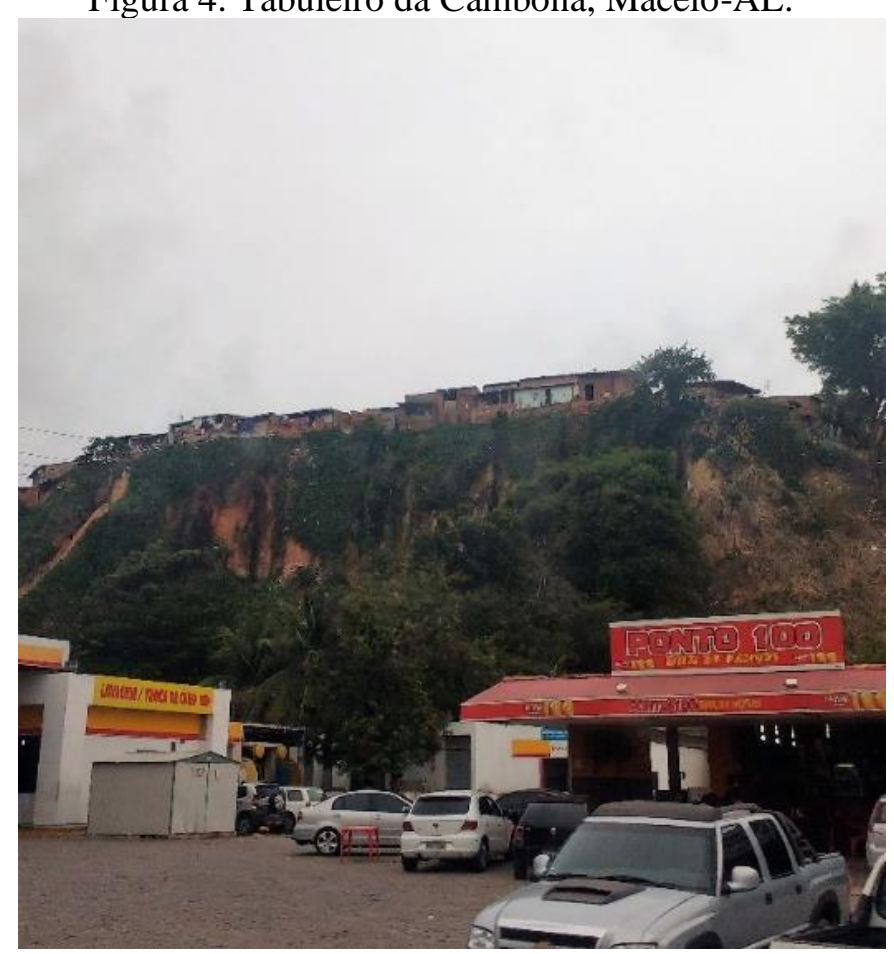

Acervo: Santos, J. J. (19/12/2016).

Contudo, essa rodovia - hoje avenida Menino Marcelo - foi, como relatado anteriormente, um forte atrativo à concentração urbana. Com o passar dos anos, os canaviais foram sendo substituídos por conjuntos habitacionais atraídos pela instalação de indústrias no Polo Multissetorial Governador Luiz Cavalcante, onde, em poucas décadas transformou por completo uma área rural em urbana, com alto índice de concentração humana. É importante frisar, segundo Villaça (2001, p. 91) - assim como na cidade do Rio de Janeiro -, "[...] o poder das vias de transportes em direcionar a expansão urbana, que predominou embora as características físicas do terreno não lhe fossem favoráveis.

É possível perceber que a expansão da cidade no decorrer dos anos passou por um misto entre o planejamento e improviso. Grandes bairros foram criados a partir de conjuntos habitacionais sem ligação entre si, ocasionando, atualmente, um caos relacionado à mobilidade urbana na cidade. Além disso, há uma grande diferenciação entre a parte baixa da cidade onde estão localizadas as praias turísticas e o restante da cidade ao subir o tabuleiro. Essas diferenças ocasionam sérios problemas aos moradores da cidade. É preciso que haja modificações nas diversas conjunturas ligadas à infraestrutura urbana para que seja possível dar um melhor trato à cidade para que fique agradável, assim como é para os turistas, para os seus moradores.

\section{COMUNIDADE OCULTA: VILA DOS PESCADORES DO JARAGUÁ, MACEIÓ-AL}

A existência de uma comunidade de pescadores numa orla marítima urbana, como é o caso da Vila de Pescadores do Jaraguá (Figura 5) em Maceió, foi colocada em xeque ao ser considerado pelos gestores de tal cidade como um entrave frente ao desenvolvimento turístico urbano. A interferência nesta comunidade traz à tona o processo de desconstrução da vida social pela imposição do poder público, para Ferraz (1996): 
Ao pretenderem introduzir modificações no ambiente físico de uma cidade, as pessoas, sobretudo aquelas possuidoras de certa parcela de autoridade, lançam mão de elementos imateriais como: objetivos, desejos, teorias, valores, pressões, necessidades, liberdade etc., sem procurarem compreender a maneira pela qual esses elementos imateriais podem exercer seu papel na orientação de mudanças e, o que é mais funesto, sem indagarem de onde vem esses elementos imateriais. (1996, p. 131)

Sobre o desenvolvimento turístico, Coriolano (2006) afirma que:

Torna-se cada vez mais evidente o processo de inclusão/exclusão na nova configuração e reprodução da economia mundial, embora, em termos de proporções, sejam bastante diferentes, porque enquanto a inclusão é para alguns, a exclusão é para muitos. (2006, p. 178).

Figura 5. Localização da Vila de Pescadores do Jaraguá - ao lado do Porto de Maceió.

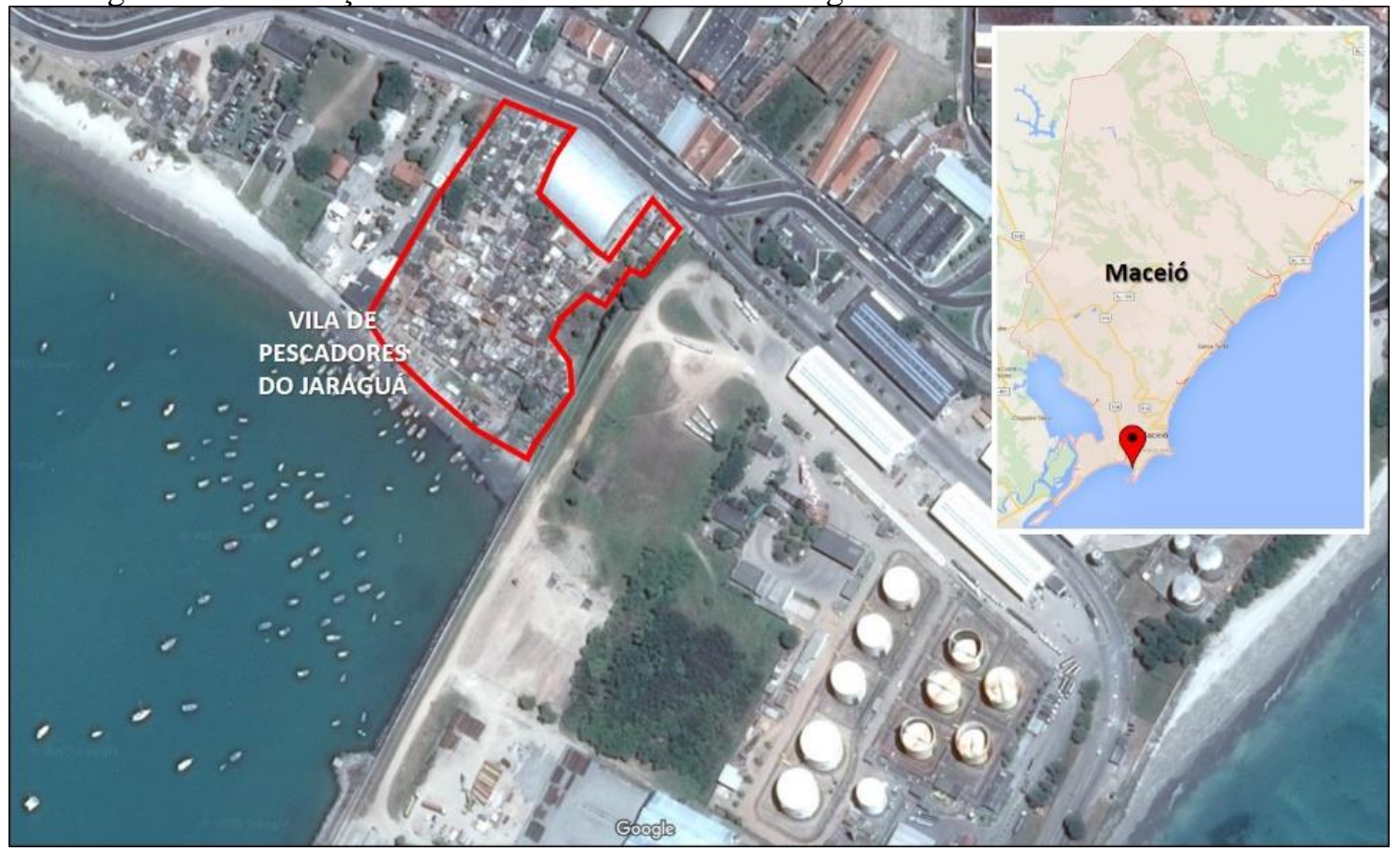

Fonte: CNES/Astrium - Google 2015. (Organizado pelo autor)

O Bairro Jaraguá é apontado por diversos historiadores como nascedouro da cidade de Maceió. Afirma-se que a expansão da cidade se deu pela força do comércio de pescados provenientes dos moradores locais. Indícios apontam ainda para o favorecimento do comércio da comunidade, à época, com o surgimento do Engenho Massayó, engenho este que deu origem ao atual nome da cidade. Para Pereira (2005):

A pesca era a atividade mais antiga do bairro, na verdade o que deu origem ao lugar. Muitos atribuem o crescimento do local ao desenvolvimento comercial, mas há quem sustente que a origem do bairro está totalmente vinculada à presença da vila dos pescadores. (2005, p. 84). 
Em uma época ainda escravocrata, a produção de cana-de-açúcar dominou a economia do nordeste brasileiro. As condições adequadas ao escoamento da produção via meios marítimos tornou o Jaraguá como pedra fundamental à constituição da cidade de Maceió. Com o avanço da cidade e a inserção de novas tecnologias, a tradição pesqueira da região começou a declinar devido, principalmente, às dificuldades enfrentadas pelos pescadores frente à concorrência agroindustrial que determinava a forma do desenvolvimento da cidade de Maceió.

As atividades de cunho tradicional que eram observados na Vila de Pescadores possuía um encadeamento entre as pessoas da comunidade. A pesca envolve a contribuição e serviços que vão além do pescador, propriamente dito. Para a prática pesqueira há o envolvimento dos tecedores de redes de pesca, os construtores e mecânicos de barcos, canoas e jangadas, os atravessadores para a comercialização final do produto, além das mulheres - geralmente um trabalho unicamente feminino - responsáveis pela catação e limpa dos mariscos, dentre outros profissionais que possam estar inseridos nesta cadeia. Cavalcante (2017) considera esse encadeamento como fundamental à comunidade e, ainda:

\begin{abstract}
Tais dados indicam a importância da manutenção da comunidade de pescadores tradicionais naquela localidade. A identidade de sua moradia com seu local de trabalho ultrapassa a atividade econômica da cadeia produtiva, pois o território significa o elo do agrupamento social com sua cultura, tradição, usos e costumes. Por isso, a importância em se proteger os territórios tradicionais. (CAVALCANTE, 2017, p. 29)
\end{abstract}

Apesar disso, por ser uma atividade tradicional, nem sempre os filhos dos pescadores escolhiam continuar com a tradição. Dessa forma, a Vila de Pescadores, com o crescimento e desenvolvimento da cidade perdeu espaço, além da falta de infraestrutura urbana, passando por um processo de favelização com habitações subnormais.

Devido à sua localização - proximidade do Porto e de bairros nobres, além de ser o caminho às diversas praias turísticas do litoral sul de Alagoas - o Jaraguá é uma região de especulação imobiliária. A recente revitalização da região portuária atraiu os olhares do setor imobiliário sendo isso uma das possíveis ascendências à retirada da Vila de Pescadores desse local. Machioni (2016, p. 35) relata que "esse processo de lutas pelo espaço territorial na cidade, em que os "enclaves periféricos" ou "ilhas de ruralidade" passam a ser o objeto de conquista pelo mercado imobiliário, vem sendo identificado em outros estudos na mesma cidade".

A expulsão dos moradores da comunidade compromete o vínculo afetivo com o local, além de eliminar parte da história do surgimento da própria cidade. Poder-se-ia urbanizar a comunidade sem precisar retirar os moradores do local. A história da Vila de Pescadores do Jaraguá poderia ter continuidade, mas por imposição do poder público, foi preciso ser dado um ponto final à história da vila sendo, os moradores, obrigados a reconstruírem suas histórias em outro local. Segundo Ferraz (1996, p. 132), "evidentemente, os indivíduos sentem-se atingidos em sua liberdade quando o ambiente físico é modificado, porque prevalece indicar uma transformação mental".

As primeiras propostas de revitalização do Bairro Jaraguá nas últimas décadas tiveram início a partir da Resolução do Conselho Estadual de Cultura e de Preservação do Patrimônio Histórico, Artístico e Natural, posteriormente homologada pelo Decreto Estadual no 6.061 de 19 de novembro de 1984. No decreto há a descrição do estudo para revitalização do centro histórico do Jaraguá com a proposta de tombamento do acervo cultural do bairro.

A resolução determinava, dentre outros pontos, que fossem mantidas as características arquitetônicas e os traços culturais do bairro, inclusive relacionados às tradições e costumes das 
pessoas que ali residiam. $\mathrm{E}$, ainda:
RESOLUÇÃO No 02 de 16 de abril de 1984.
2. RESOLUÇÃO QUANTO ÀS EDIFICAÇÕES; [...]
a. Serão efetuadas obras de conservação e/ou restauração no caso de se tratarem de edifícios antigos preservados. [...] d. Serão efetuadas obras de construção m [SIC] terrenos vazios onde não haja legislação em contrário. [...]
g.A favela situada a beira mar, constitui um caso à parte, não estando sujeita às normas estabelecidas anteriormente. Sugerimos, portanto que seja elaborado um estudo quanto aos diversos aspectos inerentes a sua implantação, devendo o mesmo ser analisado pelos órgãos competentes tais como SPHAN, CECP e Prefeitura Municipal.

A favelização da Vila dos Pescadores tornou um empecilho ao fim que o bairro estava sendo levado: turismo. Apesar de o próprio poder público, segundo Pereira (2015), recolher vítimas de desastres naturais e moradores de ruas e encaminhá-los à vila para residirem, ela - a vila passou a ser um problema frente às novas características do Jaraguá.

Em 1997 a Prefeitura de Maceió apresentou o primeiro projeto de reestruturação da Vila dos Pescadores do Jaraguá. No projeto as 273 famílias residentes à época teriam a garantia de moradia ao local que ficou conhecido como Projeto Pascoal. Em 1998, tramitava, segundo Cavalcante (2017), na então Delegacia de Patrimônio da União um processo administrativo para a cessão da área da Vila à prefeitura de Maceió, segundo ela:

\begin{abstract}
A intenção era criar uma infraestrutura no local para acomodar as 300 famílias restantes em moradias mais dignas e com melhores condições de trabalho. O procedimento, que teve início em 10 de março de 1998, foi ultimado em 18 de outubro de 2004, com a celebração do contrato de cessão, sob a forma de utilização gratuita entre a União e o Município de Maceió da área solicitada pela edilidade, destinando-a ao projeto de 'revitalização do bairro de Jaraguá' com a 'reurbanização da Vila dos pescadores'. (CAVALCANTE, 2017, p. 30)
\end{abstract}

Segundo acordo da cessão, a prefeitura deveria, até 17 de outubro de 2005, iniciar as obras que deveriam findar em 17 de outubro de 2008. No entanto, a execução do projeto não foi à frente, mesmo após a intervenção do Ministério Público por meio de processo administrativo.

A primeira remoção, e acordo com Pereira (2015), ocorreu em 2001 com a transferência de 350 famílias para um conjunto habitacional na parte alta da cidade, há cerca de $20 \mathrm{~km}$ da Vila. O motivo da remoção das famílias era o crescimento da violência na região - roubos, furtos e assaltos - atribuída pelo estado aos que habitavam na favela. E, como relata Pereira (2015):

Durante o processo de remoção houve uma polêmica, desnecessária, sobre a real historicidade da vila, uma vez que a Prefeitura não concorda com a tese de que a história da cidade teria surgido de uma vila de pescadores, sustentando sua tese num mapa de 1973, em que a vila não aparece. (PEREIRA, 2015, p. 32)

É preciso considerar que:

Ao retratar um local em duas dimensões por meio de um mapa é preciso

$\begin{array}{llllll}\text { ReVista Contexto Geográfico } & \text { Maceló-AL } & \text { V.5. N.9 } & \text { JULho/2020 } & \text { P. } 57-73 & \text { PÁGINA } 65\end{array}$


levar em conta os principais pontos e principais características deste local. Muitas vezes, por não estar inserido no contexto desse local, o cartógrafo, às vezes, peca em relação a algumas das características como: o destaque ou mesmo ausência de locais importantes para a população local. (SANTOS, 2014, p. 8)

O argumento sustentado pela prefeitura não leva em consideração todos os demais quesitos. Um mapa, apenas, sem a representação em um determinado momento não prova a inexistência da importância de um lugar. Até porque, nem sempre o que é evidenciado e sentido pela população é inserido num mapa, ele pode ocultar lugares e espaços que são importantes a determinados grupos, mas que assim não são para quem o elabora.

A Lei 5.593 de 8 de fevereiro de 2007 instituiu o Código de Urbanismo e Edificações do Município de Maceió. Nesta Lei, o Bairro Jaraguá foi catalogado como área de incentivo ao turismo, onde deveriam ser investidos, com recursos públicos e privados, em benfeitorias para tornar o bairro como um atrativo turístico à cidade. E, ainda:

\section{TÍTULO I}

\section{DAS DIRETRIZES GERAIS}

CAPÍTULO II

\section{DA ZONA ESPECIAL DE PRESERVAÇÃO CULTURAL 1 (JARAGUÁ)}

Art. 50. A Zona Especial de Preservação Cultural 1 (ZEP-1 Jaraguá) é constituída pelo sítio histórico de Jaraguá, tendo sua preservação direcionada à vocação comercial, de moradia, de lazer, de cultura e de turismo.

$[\ldots]$

TÍTULO II

DAS CONDIÇÕES ESPECÍFICAS PARA OCUPAÇÃO E EDIFICAÇÃO

CAPÍTULO I

DAS ZONAS ESPECIAIS DE PRESERVAÇÃO CULTURAL

SEÇÃO II

Da Zona Especial de Preservação 1 (Jaraguá)

$[\ldots]$

Subseção II

Do Setor de Preservação Rigorosa

Art. 379. Na faixa de praia situada entre a Avenida Major Cícero Toledo e a rebentação, será implantado projeto de agenciamento, priorizando-se o uso para:

I - jardins;

II - estacionamento;

III - equipamentos públicos necessários ao estímulo turístico e ao lazer, planejados e executados pelo Poder Público Municipal com o objetivo de prover com áreas de apoio a ZEP 1, tais como:

a) Marina;

b) Parque aquático;

c) Aquários.

A implantação da Marina e do Terminal Turístico do Porto de Maceió tornou a Vila como principal ponto para gentrificação - leia-se aqui como expulsão - da região. No projeto (Figuras 6 e 7) proposto a ideia é realmente o embelezamento da região com a construção e revitalização de vários espaços, além de paisagismo que não insere a comunidade como parte dessa reconstrução. 
Figura 6. Esquema com a localização dos equipamentos do Centro pesqueiro.

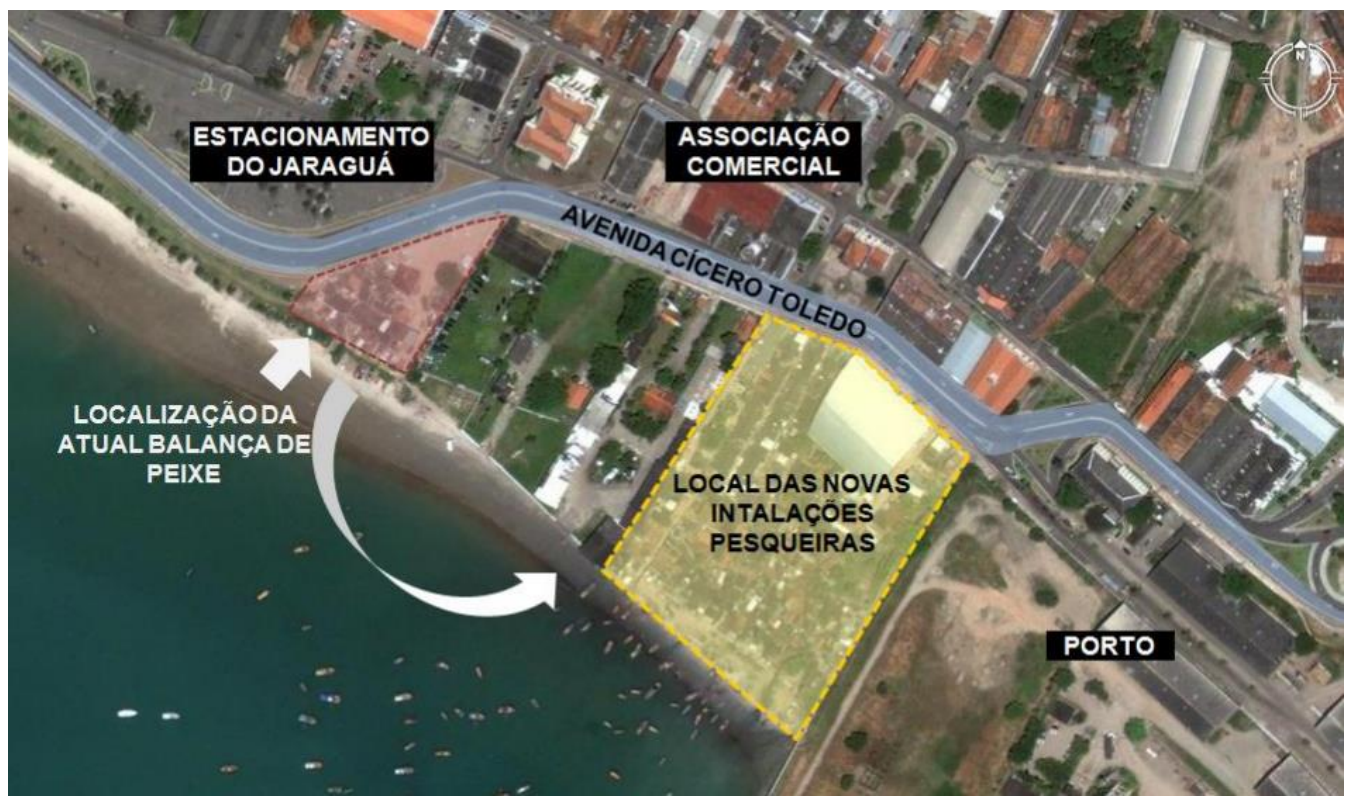

Fonte: Prefeitura de Maceió, disponível em: http://www.maceio.al.gov.br/wpcontent/uploads/admin/documento/2014/07/Centro-Pesqueiro-de-Jaragu\%C3\%A1.pdf

Figura 7. Projeto Centro Pesqueiro.

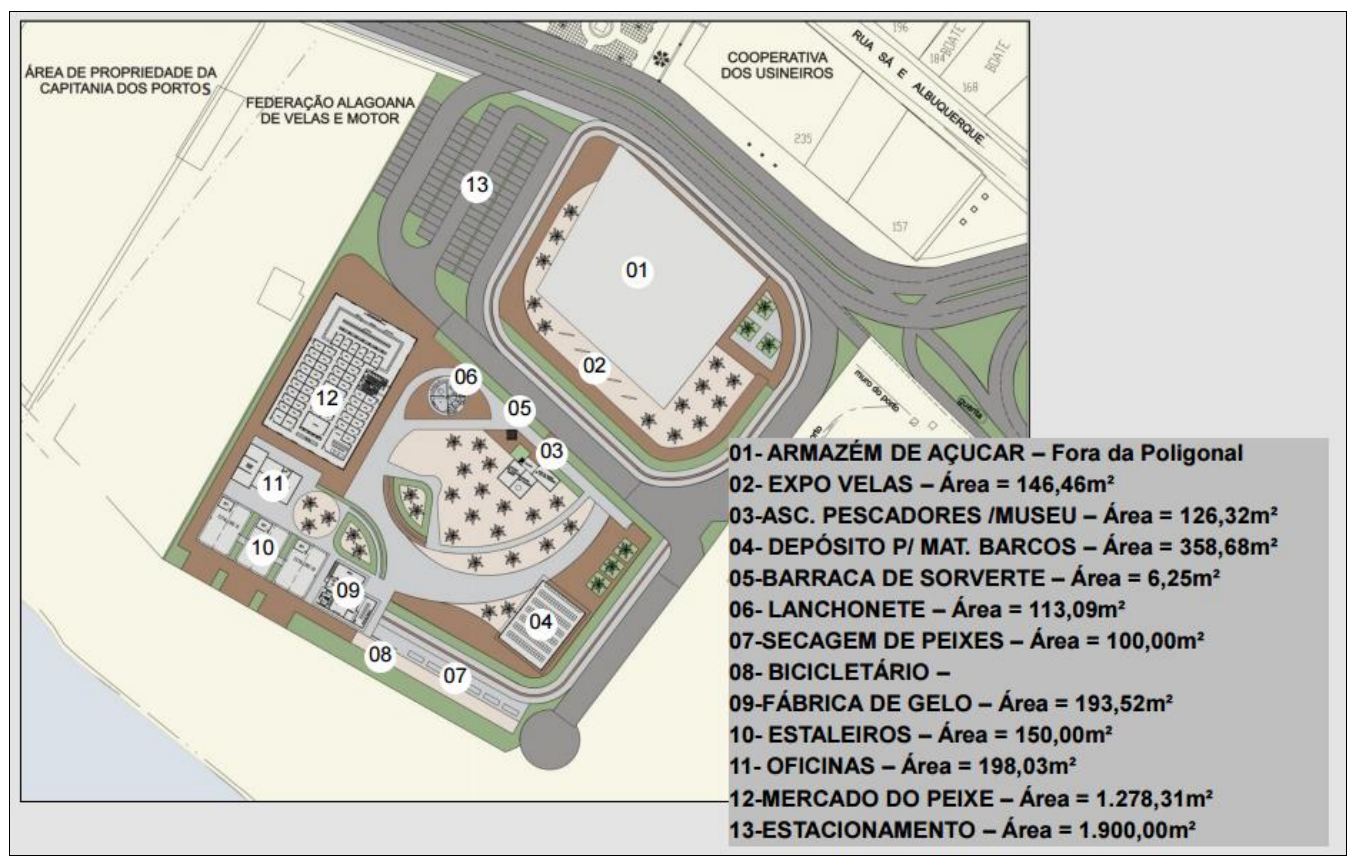

Fonte: Prefeitura de Maceió, disponível em: http://www.maceio.al.gov.br/wpcontent/uploads/admin/documento/2014/07/Centro-Pesqueiro-de-Jaragu\%C3\%A1.pdf

A retirada de 450 famílias residentes na favela do Jaraguá teve início em 2013 com o ingresso da Ação Civil Pública por parte da prefeitura de Maceió. Desde então, o processo de retirada e transferência dos moradores tem sido conflituosa. De acordo com Marchioni (2016): 
Mesmo vivendo em habitações precárias, muitas delas sob risco de incêndio, sem energia elétrica, água potável ou saneamento básico, cerca de 150 famílias preferem permanecer no local do que serem removidas para o Conjunto Habitacional no Pontal da Barra, construído pela Prefeitura. Segundo relatos dos próprios moradores, a opção de 150 famílias pela permanência no local estava relacionada para além da atividade econômica de subsistência, compreendendo também os costumes tradicionais e os laços culturais e de pertencimento daquela comunidade. (MARCHIONI, 2016, p. 29-30).

Segundo o site de notícias G1-Alagoas, em 17 de junho de 2015, os últimos moradores da comunidade foram retirados após a concessão dada pela Primeira Turma do Tribunal Regional Federal da $5^{\text {a }}$ Região (TRF 5), do pedido de desocupação feito pela prefeitura de Maceió. A resistência à saída por parte dos moradores foi de cunho pacífico, restando apenas um último registro fotográfico da luta (Figura 8) pela permanência e continuidade da história da comunidade.

Figura 8. Registro da luta pela permanência e continuidade da história da Vila de Pescadores do Jaraguá, Maceió-AL.

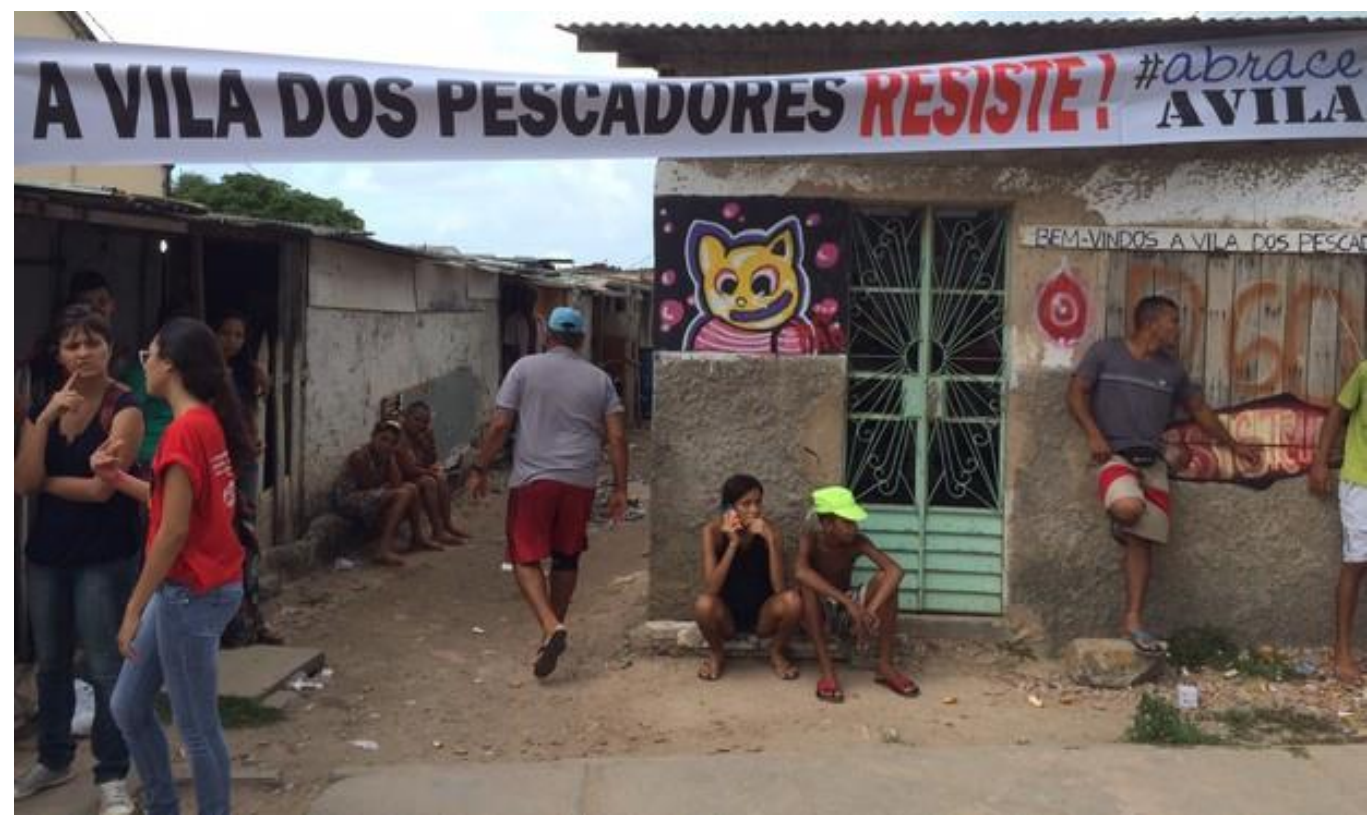

Foto: Pedro Mesquita/G1, disponível em: http://g1.globo.com/al/alagoas/noticia/2015/06/comecaoperacao-para-desocupar-favela-de-jaragua-em-maceio.html

Das 150 famílias restantes, 25 foram transferidas para o Conjunto Habitacional da Praia do Sobral (Figura 9). Quanto às demais, foram-lhes assistidas somente o auxílio-moradia por tempo determinado. A questão do pertencimento ao lugar foi desconsiderada por parte da prefeitura, já que, mesmo sob protestos dos moradores, o projeto de retirada continuou a fim de dar lugar a uma obra que, segundo a prefeitura, revitalizaria a região portuária para dar suporte à chegada de turistas via Cruzeiro Marítimo. 
Figura 9. Atual localização da Vila dos Pescadores na Praia do Sobral, Maceió/AL.

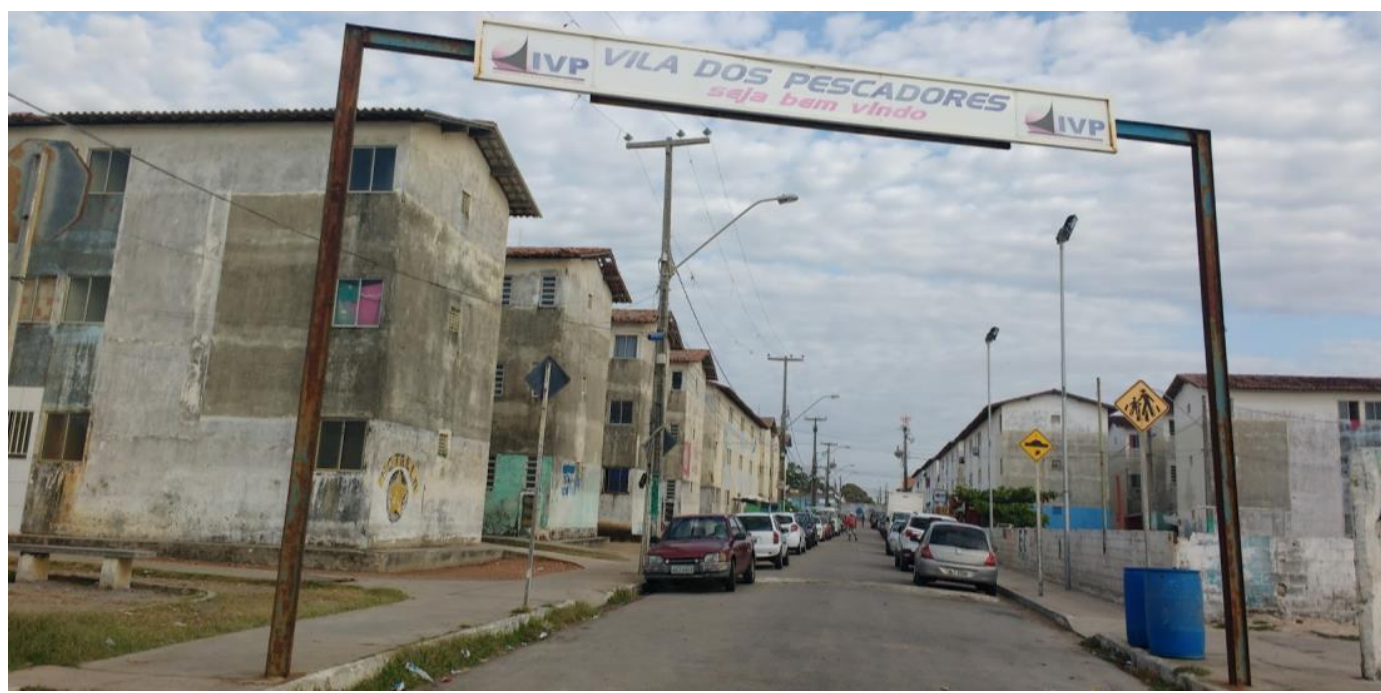

Foto: Jadson de Jesus Santos, em 8 de novembro de 2017.

A obra (Figura 10), em andamento, do Centro Pesqueiro terá uma marina, balança de peixes e o Museu do Pescador, este, segundo a prefeitura, mostrará a tradição pesqueira da antiga comunidade tradicional que ali residia, resgatando a história da comunidade. O poder público desconsiderou, dessa maneira, a continuidade da história da comunidade, ficando apenas como objeto de mostras históricas em um museu para futuros visitantes. Segundo Machioni (2016):

A comunidade pesqueira de Jaraguá, também chamada de Vila dos Pescadores de Jaraguá, é contemporânea à formação de Maceió e cresceu à medida que aumentava o fluxo migratório dos trabalhadores rurais e da pesca de outras cidades para a capital alagoana. (MARCHIONI, 2016, p. 31)

Figura 10. Perspectiva do projeto de intervenção da área da antiga Vila de Pescadores do Jaraguá.

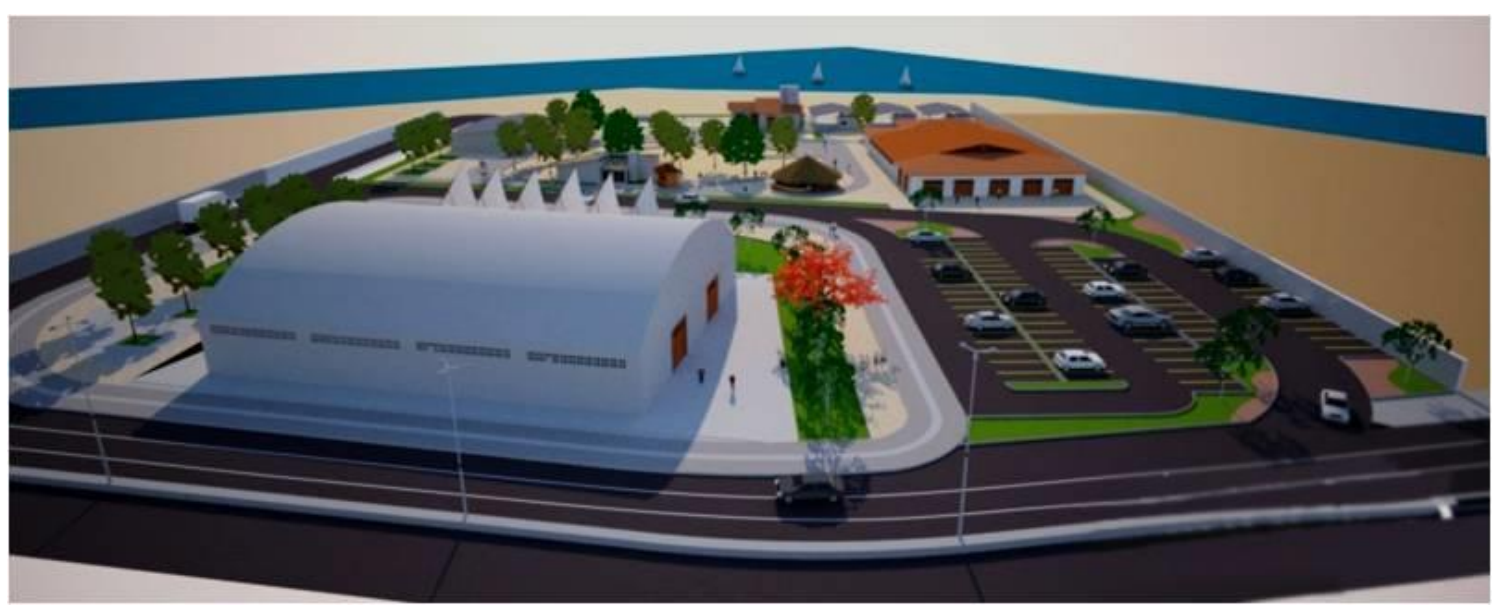

Foto: SECOM-Maceió, disponível em: http://www.maceio.al.gov.br/2015/06/prefeitura-cumpre-decisaojudicial-para-desocupar-favela-de-jaragua/ 
A prefeitura alega, que a área não poderia ser beneficiada por um projeto habitacional devido a um parecer técnico do Instituto do Meio Ambiente (IMA) o qual afirma que:

[...] por possuir baixa dinâmica costeira causada pelo aterro do Cais do Porto que intercepta à deriva litorânea e também pelos terminais de atracação que protegem a costa local da energia das ondas e correntes, paralelos à Favela de Jaraguá. Dessa forma, os dejetos lançados ao mar pela população da favela ficam acumulados naquela região, o que resulta em uma água com altíssimos índices de contaminação por coliformes totais e fecais nas marés mais baixas, e o material contaminado fica depositado na faixa de areia da localidade. (Fonte: Prefeitura de Maceió).

De acordo com dados da Prefeitura de Maceió, a verba para reurbanização do local é proveniente do Ministério das Cidades, de R \$ 19 milhões, e contrapartida do município, de R\$ 4,6 milhões, totalizando $\mathrm{R}$ \$23,6 milhões divididos entre o projeto de habitação, que já foi concluído com a construção do residencial, do Centro Pesqueiro, além da ampliação da Escola Municipal Antídio Vieira, no Trapiche.

Mesmo tendo o reconhecimento de comunidade tradicional, o Judiciário Federal, assinado pelo então ministro Ricardo Lewandowski, tomou como decisão:

1) determinar a desocupação, no prazo de até 90 (noventa) dias, de todos os ocupantes da área reivindicada (coletividade invasora e os remanescentes/dissidentes da comunidade tradicional de pescadores que ainda ocupam a área objeto do presente conflito, quer sejam cadastrados ou não na lista oficial da municipalidade);

2) determinar a transferência das famílias - devidamente cadastradas pelo Município de Maceió-AL - remanescentes da comunidade de pescadores do Bairro de Jaraguá, ora reconhecida como tradicional, para os imóveis da Vila dos Pescadores, localizados na Av. Sobral, à beira-mar, no bairro do Sobral, em Maceió/AL, (...);

As constantes modificações dos projetos, onde, inicialmente, o foco era a manutenção das pessoas no local, foram ocorrendo ao ponto de, no último suspiro da comunidade, serem transferidos definitivamente. A ideia atual é que, na concepção de Cavalcante (2017):

\begin{abstract}
A própria remodelagem do bairro de Jaraguá visualizada nos últimos anos conduz aos propósitos da 'Cidade-Mercadoria' e 'Cidade-Empresa': em sua orla marítima, emolduram-se obras arquitetônicas voltadas para o turismo cultural, como o Memorial da República, o coreto e dois grandes estacionamentos, que parecem ser complementadas como o centro pesqueiro e a reestruturação da área da balança de peixe. Ainda na orla, tem-se o Porto de Jaraguá, o clube da Polícia federal, uma área da Capitania dos Portos e a Federação Alagoana de Velas e Motor, quer dizer, um conjunto de instituições vocacionadas a promover o turismo e o lazer náutico, como previu o Plano Diretor. (CAVALCANTE, 2017, p. 36).
\end{abstract}

O foco atual da prefeitura na região é quase exclusivamente voltado ao turismo - além das atividades portuárias - onde o intuito é interligar todas essas regiões num panorama voltado às 
atividades turísticas. Inclusive, diversas manifestações culturais são celeradas na região dos estacionamentos do Jaraguá como é o caso dos festejos juninos e do Festival de Verão de Maceió que ocorre em janeiro - mês da alta temporada turística alagoana

\section{CONSIDERAÇÕES FINAIS}

Considerar comunidades tradicionais como um problema à cidade é trazer à tona a falta de planejamento que garanta a todos o direito à moradia. A moradia não se trata apenas de um espaço físico, ela é, também, o pertencimento ao espaço de vivência adquiridos ao longo da vida de cada um. Garantir a todos o direito à moradia é garantir o direito a viver em comunidade a qual pertence cada um dos indivíduos.

$\mathrm{O}$ que se pode considerar neste histórico apresentado é que o intuito inicial de moradia digna e manutenção da comunidade no seu lugar modificou-se ao longo do tempo. A ideia de resolver problemas sociais ligados às condições adequadas de vida aos moradores só foi - ou está sendo - concretizada devido à mudança de visão por parte do poder público. Se o foco do bairro não tivesse sido modificado ao cunho turístico, será que as famílias de pescadores estariam hoje, mesmo que em outro local, vivendo em moradias com infraestrutura mais adequada?

Ao transformar a cidade em uma paisagem gentrificada com o intuito de atrair turistas devem-se considerar, também, as possibilidades de manutenção dos moradores em seu espaço de vivência. A moradia, mais uma vez, não é apenas um espaço físico construído. A moradia é o lugar de cada um, onde se sente como seu, se sente bem, criam-se vínculos de amizade, vínculos de uma comunidade propriamente dita.

Essas questões devem ser levadas em consideração no tocante às reestruturações dadas aos ambientes urbanos. A qualidade de vida é o conjunto de condições e sentimentos dados às vivências entre as pessoas. $\mathrm{O}$ turismo não deve ser desconsiderado, pelo contrário, ele deve ser levado em consideração, mas a supressão da comunidade frente a ele não deve acontecer. A harmonia entre os dois deve ser considerada como quesito à melhoria dos espaços urbanos aos residentes e aos visitantes.

\section{AGRADECIMENTOS}

O presente trabalho foi realizado com o apoio da Coordenação de Aperfeiçoamento de Pessoal de Nível Superior - Brasil (CAPES) - Código de Financiamento 001.

\section{REFERÊNCIAS}

ALAGOAS, Estado de. Decreto no 6061 de 19 de novembro de 1984. Homologa Resolução do Conselho Estadual de Cultura e de Preservação do Patrimônio Histórico, Artístico e Natural. Disponível em: <http://www.cultura.al.gov.br/politicas-e-acoes/patrimonio-cultural/principal/legislacoes/decreto-no6061-1984>. Acesso em 11 de junho de 2017.

BRASIL. Superior Tribunal de Justiça. Trata-se de suspensão de segurança proposta pelo Município de Maceió contra a antecipação de tutela proferida pela $1^{\mathrm{a}}$ Turma do Tribunal Regional Federal da $5^{\mathrm{a}}$ Região, nos autos dos Agravos de Instrumento n. ${ }^{\circ}$ 0007542-05.2014.4.05.0000 e 0007541-20.2014.4.05.0000, na qual foi conferido efeito suspensivo ao recurso de apelação interposto pela AMAJAR - Associação dos Moradores e Amigos do Bairro de Jaraguá e pela COLETIVIDADE "INVASORA" DA FAVELA DO JARAGUÁ. Relator: Ricardo Lewandowski. Diário Justiça. Brasília, $1^{\circ}$ de outubro de 2015. Disponível em:

<http://www.stf.jus.br/portal/diarioJustica/verDecisao.asp?numDj=202\&dataPublicacao=08/10/2015\&inc idente $=4684428 \&$ capitulo $=6 \&$ codigoMateria $=7 \&$ numeroMateria $=147 \&$ texto $=5454788>$. Acesso em 10 de junho de 2017. 
CAVALCANTE, Fátima Maria Lyra. A Vila dos pescadores de Jaraguá e a sua interação com a política de revitalização do centro histórico: a reurbanização do espaço público e a exclusão social. In: Revista Olhares Plurais, $\mathrm{n}^{\mathrm{o}}$ 16, vol. 1, ano 2017. ISSN 2176-9249. Disponível em: <http://revista.seune.edu.br/index.php/op/article/download/256/198>. Acesso em 13 de junho de 2017.

CEFET-AL. A história do meu bairro. $\mathrm{n}^{\circ} 1$, ano 1. Maceió, 2002.

CORIOLANO, Luzia Neide Menezes Teixeira. O turismo nos discursos, nas políticas e no combate à pobreza. São Paulo: Annablume, 2006.

FERRAZ, Hermes. Cidade e vida. São Paulo: João Scortecci, 1996.

G1-ALAGOAS. Começa operação para desocupar favela de Jaraguá, em Maceió. Disponível em: <http://g1.globo.com/al/alagoas/noticia/2015/06/comeca-operacao-para-desocupar-favela-de-jaragua-emmaceio.html>. Acesso em: 7 de dezembro de 2015.

Alagoas tem aumento no número de turistas pelo quarto ano consecutivo. Disponível em: <https://g1.globo.com/al/alagoas/noticia/alagoas-tem-aumento-no-numero-de-turistas-pelo-quarto-anoconsecutivo.ghtml>. Acesso em: 20 de fevereiro de 2019.

GOOGLE EARTH ENGINE. Timelapse: Maceió, Alagoas, Brasil. Disponível em: $<$ https://earthengine.google.com/timelapse/\#v=-9.64149,-35.71632,9.848,latLng\&t=2.79>. Acesso em 12 de dezembro de 2016.

IBGE. IBGE divulga as estimativas populacionais dos municípios para 2017. Disponível em: <https://agenciadenoticias.ibge.gov.br/agencia-noticias/2013-agencia-de-noticias/releases/16131-ibgedivulga-as-estimativas-populacionais-dos-municipios-para-2017.html>. Acesso em 26 de janeiro de 2018.

Cidades 2010). Disponível em: <https://cidades.ibge.gov.br/brasil/al/maceio/panorama>. Acesso em 15 de abril de 2020.

MACEIÓ, Prefeitura de. Lei Municipal No 5.593, de 08 de fevereiro de 2007. Institui o Código de Urbanismo e Edificações do Município de Maceió, estabelece o zoneamento da cidade de acordo com os Parâmetros de Macrozoneamento do Plano Diretor de Desenvolvimento Urbano (Lei Municipal n. 5.486, de 30 de dezembro de 2005) e dá outras providências. Disponível em: <http://www.maceio.al.gov.br/wpcontent/uploads/admin/documento/2013/11/Lei-Municipal-5.593-de-08-de-Fevereiro-de-2007-

C\%C3\%93DIGO-DE-URBANISMO-E-EDIFICA\%C3\%87\%C3\%95ES-DO-MUNIC\%C3\%8DPIO-DEMACEI\%C3\%93.pdf>. Acesso em 11 de junho de 2017.

Conheça a nova estrutura de apoio à pesca no bairro de Jaraguá. Disponível em: <http://www.maceio.al.gov.br/centropesqueiro/>. Acesso em: 7 de dezembro de 2015.

MARCHIONI, Alessandra. Comunidade da Vila dos Pescadores do Jaraguá, Maceió/AL e a (in) efetividade do Direito Internacional ("Direito à Moradia Adequada"). Revista Eletrônica do Mestrado em Direito da UFAL. V. 7, N. 1 (2016). ISSN 2237-2261. Disponível em: <http://www.seer.ufal.br/index.php/rmdufal/article/view/2557/2184>. Acesso em 10 de junho de 2017.

MINISTÉRIO DO TURISMO. Anuário Estatístico de Turismo - 2019. Volume 46, ano base 2018. Disponível em: <http://www.dadosefatos.turismo.gov.br/2016-02-04-11-5305/item/download/1120_3aae1d736436b6020ef93db77057e198.html>. Acesso em: 15 de abril de 2020.

PEDROSA, José Fernando de Maya. Histórias do Velho Jaraguá. Maceió: Editora Talento, 1998.

PEREIRA, Parmênides Justino. Urbano, demasiadamente humano: uma reflexão político-afetiva da remoção de moradores da comunidade Jaraguá. Dissertação de Mestrado. UFAL. Mestrado em Sociologia, Maceió: 2005

Educação popular e consciência política na luta pelo espaço urbano: a resistência da Vila de Pescadores do Jaraguá. Tese de Doutorado. UNICAMP. Doutorado em Educação, Campinas-SP: 2015. Disponível em: <http://taurus.unicamp.br/bitstream/REPOSIP/254026/1/Pereira,\%20Parm\%3Fnides\%20Justino_D.pdf>. Acesso em 11 de junho de 2017. 
PNUD, Programa das Nações Unidas para o Desenvolvimento. Ranking decrescente do IDH-M dos municípios do Brasil. Atlas do Desenvolvimento Humano. 2010. Disponível em: $<$ http://www.undp.org/content/brazil/pt/home/>. Acesso em: 07 de setembro de 2016.

SANTOS, Jadson de Jesus. Visões Cartográficas de Itabaiana-SE. Dissertação de Mestrado. UFS. Programa de Pós-Graduação em Desenvolvimento e Meio Ambiente, São Cristóvão-SE: 2014. Disponível em: 〈https://bdtd.ufs.br/bitstream/tede/1295/1/JADSON_JESUS_SANTOS.pdf>. Acesso em 11 de junho de 2017.

VILLAÇA, Flávio. Espaço intra-urbano no Brasil. 2a edição. São Paulo: Livros Studio Nobel, 2001. ${ }^{1}$ Armazém onde se guardam mercadorias para embarque, junto ao cais. 2 - Pequeno engenho de cana-de-
açúcar. Disponível em: 〈https://dicionariodoaurelio.com/trapichè. Acesso em: 26 Jan. 2020 